\title{
10 years of Malaria Journal: how did Open Access change publication patterns?
}

Marcel Hommel

\section{Background}

Fifteen years ago, most publications were paper-based, accessible only by subscription - be it a personal or a library subscription. By the late 1990s, this 'traditional' mode of access to scientific literature was about to change dramatically, as the result of a combination of events: the improvement of personal computer hardware (with computers becoming faster and cheaper every year), public access to internet and the world-wide web, online publishing and, most of all, the will of the scientific community to make research more easily available. This has led to the development of Open Access (OA). This revolution in publishing has given developing countries an opportunity to have access to the latest scientific literature, by-passing the need for libraries, which they could not afford.

Once 'traditional' publishers had started to produce their journals in an online format, it became possible to consider making them available free-of-charge or at low-cost to readers outside the industrialized world: this was first achieved in 2000, through the HINARI Initiative, a partnership between the World Health Organization and a number of publishers. It was a step in the right direction, but was far from providing the desired unlimited access.

In 1997, the U.S. National Library of Medicine made MEDLINE, the most comprehensive index to medical literature, freely available online in the form of PubMed: as a result, the usage of this database increased 100-fold overnight. Since access to research abstracts alone is insufficient, this quickly led to the recognition of the need for an open online repository of full articles, which was realized as PubMedCentral. Once this was in place, Vitek Tracz, the chairman of a UK-based publishing company, was able to launch BioMed Central in 2000. BioMed Central which is now part of the Springer Group, publishes 206 peer-reviewed Open Access

Correspondence: editorial@malariajournal.com Editor-in-Chief, Malaria Journal, Liverpool, UK journals, including Malaria Journal, started in 2002, and Parasite E Vectors, started in 2008. The fact that articles in BioMed Central journals are immediately backed-up in the PubMed Central repository provides them with a long-term security other online journals may not provide.

The Open Access concept really gained momentum when funding agencies in many countries, including the Wellcome Trust, the Department of Health and the Medical Research Council in the UK, made it a requirement in 2006 for the research they had financed to become freely available in open access, not later than six months after its publication. This has forced many 'traditional' non-OA journals to make articles available in limited open access, after an embargo period of 6-12 months or longer. The alternative to publishing in a journal that provides immediate OA to all of its articles on the publisher's website (such as BioMed Central's journals), is for the author to 'self-archive' in a repository (for example, in an institutional repository or in PubMed Central).

The creation of the Public Library of Science (PLoS) in 2001, initially as an organization to advocate Open Access publication, led to the creation of a number of PLoS journals initially aimed firmly at the "high quality end' of the scientific spectrum. The launch of these new journals, together with the wide range of OA journals started a few years earlier by BioMed Central, has changed the scientific publication scene forever.

\section{How did Open Access affect the publication of malaria research ?}

A PubMed search for publications on 'malaria' in 2009, shows 2,839 papers, but as bibliometric tools are imperfect, $9 \%$ of these had only a trivial malaria content and were excluded from further analysis; the same correction factor was arbitrarily applied to publications on malaria between 2002 and 2009, as shown on Figure 1. Accordingly, a total of 2,584 papers had been published in English in 2009, in 528 journals (390 of which are 


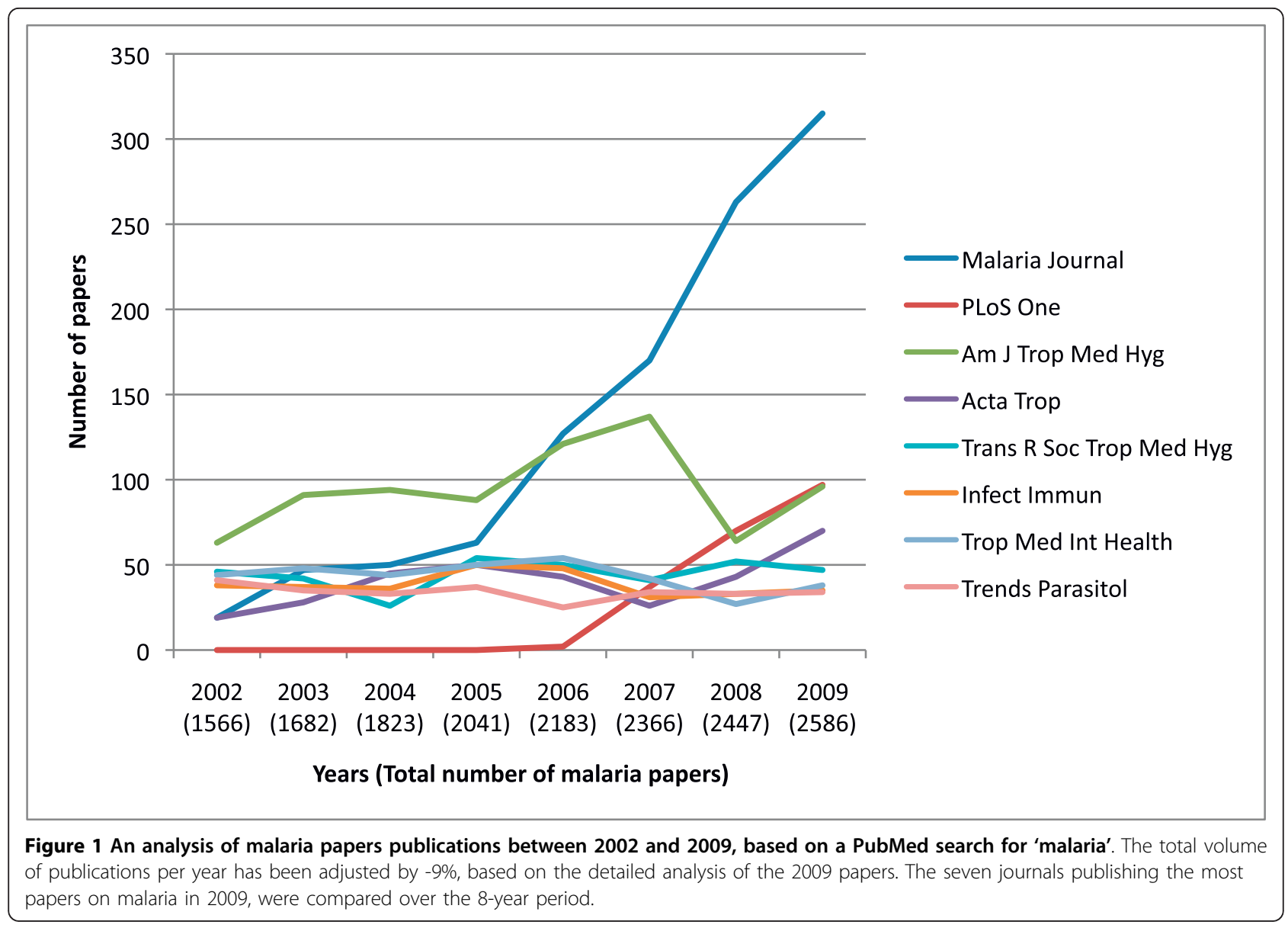

impact factor-rated)(see Additional file 1 for the list of journals analysed). The extreme variety of journals publishing papers on malaria is an indication of how wide a field 'malaria' actually covers. While the majority of journals published only one or two papers on malaria that year, the bulk of papers $(885,34.2 \%)$ was found in a group of 13 journals, each with more than 25 papers that year. An analysis of seven of these journals over a period of 8 years shows that Malaria Journal and PLos One now publish $12.1 \%$ and $3.7 \%$ of all papers, respectively, while the other journals had kept more or less the same volume of publications over the period (i.e. a relative decrease of their share in the total volume of malaria publications, which had increased from 1,566 to 2,584 papers per year over the period). By comparison, in 2002, publication of malaria papers was spread more widely than in 2009 , with 30 journals sharing about $25 \%$ of the bulk of the publication volume.

The success of the open access movement has led to the launch of many more specialist journals over the past three years, including PLoS Neglected Tropical Diseases, Parasites \& Vectors, Journal of Infection in Developing Countries, all in disciplines of interest to the scientific community working on malaria. Furthermore, Hindawi has announced the forthcoming launch of Malaria Research \& Treatment, whilst the MalariaWorld Newsletter has announced the project of a MalariaWorld Journal. In terms of improving the dissemination of information to the widest possible audience, this diversity of journals can only be a good thing. It also provides authors with a choice to best fit their needs.

Why do authors choose to publish in one journal rather than another? An author's ideal choice would deliver fast publication, in a journal that has a broad coverage and a good exposure to colleagues in their discipline, whilst also conveying 'prestige' (often taken as synonymous with having as high an impact factor as possible), and in a journal that is free-of-charge. No journal does, of course, have all these features, but on the whole, open access journals are doing better than traditional journals on most of these although availability of sufficient funding to cover open access publication fees (article processing charges, APC) remains a concern for many authors. It is notable that the 'big 10' - the journals usually considered to convey the most 'prestige' 


\begin{tabular}{|c|c|c|}
\hline Journal & $\begin{array}{c}\text { Impact Factor } \\
\text { (2009) }\end{array}$ & $\begin{array}{c}\text { Nb malaria papers } \\
(2009)\end{array}$ \\
\hline NEJM & 47 & 6 \\
\hline Nature * & 34 & 7 \\
\hline Cell & 31 & 0 \\
\hline Lancet & 30 & 28 \\
\hline Science & 29 & 7 \\
\hline J Exp Med & 14 & 1 \\
\hline PLos Medicine** & 13 & 15 \\
\hline BMJ & 11 & 18 \\
\hline Proc Natl Acad Sci USA & 9 & 14 \\
\hline J Biol Chem & 5.6 & 18 \\
\hline
\end{tabular}

Figure 2 List of the 'big-10' prestige journals, their impact factors and the number of articles on malaria published in 2009.

(see Figure 2) - published only $4.4 \%$ of the total number of malaria papers in 2009.

Journals available for immediate open access and publishing papers on malaria are still in the minority, but their importance in terms of volume of publication is increasing every year. In 2009, 31 open access journals, including Malaria Journal plus 22 other BioMed Central journals, seven PLoS journals and the BMJ published $21 \%$ of all malaria papers that year. In addition, in view of the global interest in malaria, many non-Open Access journals provide free access to occasional articles on malaria or to special issues on malaria and other tropi$\mathrm{cal} /$ neglected diseases.

\section{Impact of Open Access on Developing Countries}

Considering that over $90 \%$ of malaria mortality occurs in Africa, it is a sad observation that in the 20 Africabased medical journals listed in the PubMed search for 2009, a total of only 52 articles was published there (see Figure 3). This does not reflect any lack of African medical journals - there are many - but rather reflects the fact that many of these are still paper-based, or online via subscription only, are irregular in their production and are often not discoverable via PubMed. There is hope, however, that this situation may improve: hundreds of African online journals are now indexed and archived on AJOL (African Journals Online) and many are moving towards an open access format, sometime with assistance from various Non Governmental Organizations, such as Bioline International. Figure 2 shows that half of the journals listed in AJOL are open access and that two of them are also archived in PubMedCentral (Ghana Medical Journal and African Journal of
Traditional, Complementary, and Alternative Medicines). On the other hand, it is conceivable that the improved access to papers from 'Northern' journals may actually be a disincentive for the redevelopment of Africa-based journals - this would be a shame.

BioMed Central in general, and Malaria Journal in particular, are making a special effort to attract articles from authors in the developing world. It is often said of

African Health Sciences (OA)

African Journal of Biochemical Resesearch (OA)

African Journal of Medical Sciences

African journal of traditional, complementary,

and alternative medicines (OA/12 Months)(PubMedCentral)

Annals of African Medicine (OA)

East African Journal of Public Health (OA)

East African Medical Journal

East African Medical Health

Ethiopian Journal of Medicine

Ghana Medical Journal (OA)(PubMedCentral)

Journal of Egyptian Society of Parasitology

Malawi Medical Journal (OA)

Mali Medical Journal

Nigerian Journal of Clinical Practice

Niger Journal of Physiological Sciences

Nigerian Journal of Medicine

Nigerian Postgraduate Medical Journal

Nigerian Quarterly Journal of Hospital Medicine

Tanzanian Journal of Health Research (OA)

South African Medical Journal (OA)

Figure 3 List of Africa-based journals having published at least one paper on malaria in 2009 , showing those that are Open Access and those that use the PubMedCentral repository. None of these journals are impact factor rated. 
Open Access journals that their APCs are very high and would make it impossible for authors from the developing world to publish in them. In reality, BioMed Central is waiving APCs for authors from the poorest countries (based on a World Bank list), if they request it. In 2009, of the 315 articles published in Malaria Journal, 81 had an African scientist as first author and a further 47 had African scientists as one of the authors.

\section{Malaria Journal}

The exponential growth of Malaria Journal over the past nine years can be explained by a combination of factors: having been the first open access journal in tropical medicine, created at the very start of the Open Access movement, having a prestigious and dynamic Editorial Board, making the effort to copy-edit all articles in a traditional fashion, and helping less-experienced authors from the developing world to reshape their manuscript to an acceptable standard. Figure 4 shows the evolution of the journal over time, in terms of its impact factor, in comparison with others; Malaria Journal has now been a leader amongst specialist tropical medicine journals for a few years and the average output this year has reached a paper per day. Quality is not only judged by how often an article is cited, but also by the number of times it is consulted online: in a way, this is how readers show their interest in a paper, and this is recognized on the paper by a 'highly accessed' tag.

Since its launch almost 10 years ago, Malaria Journal has promoted itself as a journal accepting papers on 'malaria in its broadest sense and publishing exclusively papers on malaria'. It was of interest, therefore, to look at its publication output in 2009, compared to the whole field (using the 2,584 papers found through the PubMed search), as well as to one of the most respected 'traditional' tropical medicine journals, the American Journal of Tropical Medicine and Hygiene (see Figure 5). While both journals have a broad coverage of the discipline, comparing reasonably well with the overall content of papers published that year, there were substantial differences in the level of coverage: both journals covered the Biology/Biochemistry category poorly, but Malaria Journal had a better than average coverage of the Epidemiology/Control, Social Sciences/ Health Policy and Entomology/Insecticides categories, while the American Journal of Tropical Medicine and Hygiene had a better than average coverage of the Clinical category.

The main thrust of the journal is the publication of peer-reviewed Research papers (87\% of papers in 2009), but it also contains Case reports, Methodology papers, Reviews, Opinion and Commentaries. The journal produced a series of supplements, including one on 'The research agenda for global malaria elimination', one on the drug 'Coartem' and one on 'Development of the sterile insect technique for African malaria vectors'; a supplement on 'Natural products for anti-malarial drug development' is in preparation. The journal also offers the possibility of thematic series, which bring together in one section of the journal a number of papers on the same topic; one such series on 'Malaria elimination', guest-edited by M. Tanner, was started early in 2010 .

This year, the Malaria Journal and BioMed Central are organizing a three-day Conference on 'Parasite to Prevention', with the abstracts of the presentations and posters presented at the conference to be published in

\begin{tabular}{|c|c|c|c|c|c|c|c|}
\hline & 2003 & 2004 & 2005 & 2006 & 2007 & 2008 & 2009 \\
\hline PLoS Pathogens & 0 & 0 & 4.25 & 6.05 & 9.33 & 9.12 & 8.97 \\
\hline $\begin{array}{l}\text { J Infect Dis } \\
\text { Antimicrob Agents }\end{array}$ & 4.94 & 4.94 & 4.37 & 5.36 & 6.03 & 5.68 & 5.86 \\
\hline Chemother & 4.24 & 4.21 & 2.82 & 4.15 & 4.39 & 4.71 & 4.8 \\
\hline PLoS Neglected Diseases & 0 & 0 & 0 & 0 & 0 & 4.71 & 4.69 \\
\hline PLoS One & 0 & 0 & 0 & 0 & 0 & 0 & 4.35 \\
\hline Trends Parasitol & 6.78 & 5.49 & 2.02 & 4.9 & 4.96 & 4.69 & 4.29 \\
\hline Infect Immun & 3.87 & 4.03 & 3.93 & 4 & 3.99 & 3.98 & 4.22 \\
\hline Int J Parasitol & 2.88 & 3.09 & 1.22 & 3.33 & 3.39 & 3.75 & 3.81 \\
\hline Vaccine & 3 & 2.82 & 0 & 3.15 & 3.37 & 3.29 & 3.61 \\
\hline Malaria Journal & 0 & 0 & 2.13 & 2.74 & 2.47 & 2.91 & 3.00 \\
\hline Am J Trop Med Hyg & 2.1 & 2.01 & 2.48 & 2.54 & 2.67 & 2.45 & 2.79 \\
\hline Trans R Soc Trop Med Hyg & 2.11 & 1.74 & 1.66 & 2.03 & 2.13 & 2.06 & 2.55 \\
\hline Trop Med Int Health & 2.15 & 1.96 & 2.58 & 2.59 & 2.46 & 2.31 & 2.32 \\
\hline Acta Trop & 1.33 & 1.95 & 1.8 & 2.21 & 2.00 & 1.7 & 2.21 \\
\hline Ann Trop Med Parasit & 1.01 & 1.16 & 4.95 & 1.18 & 1.34 & 1.68 & 1.38 \\
\hline
\end{tabular}




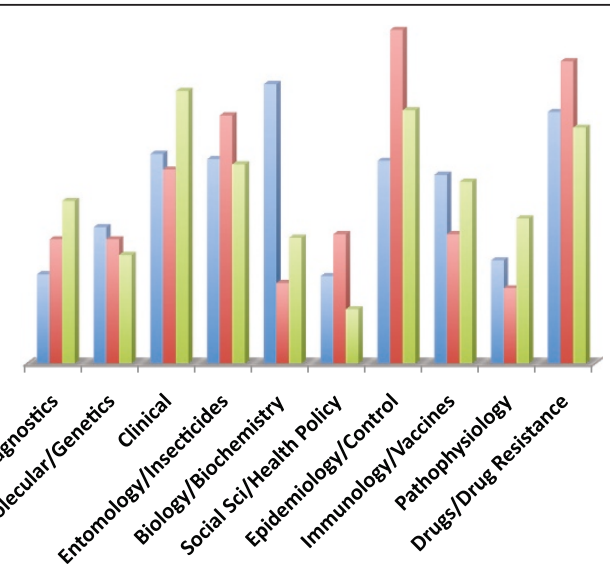

Figure 5 Comparaison of literature coverage (2009 sample): total papers published on malaria (in blue), Malaria Journal papers (in red), American Journal of Tropical Medicine and Hygiene (in green). The following categories were used: 1. Diagnostics. 2. Molecular/Genetics. 3. Clinical. 4. Entomology/ Insecticides. 5. Biology/Biochemistry. 6. Social Sciences/Health Policy. 7. Epidemiology/Control. 8. Immunology/Naccines. 9.

Pathophysiology. 10. Drugs/Drug resistance.

Malaria Journal. This is an appropriate way of marking the coming of age of the journal and be able to give some thoughts for its future.

An Editorial to mark to $10^{\text {th }}$ year of Malaria Journal could not have been written without acknowledging the work of so many colleagues who have so generously given of their time to peer-review the manuscripts submitted to the journal: their comments have helped to transforms manuscripts into quality papers, and the journal could not have worked without them.

\section{Additional material}

Additional file 1: List of the $\mathbf{5 2 8}$ journals that have published at least one malaria paper in 2009. Showing three categories: those have published more than 25 papers, those that have published between 6-24 papers, and those who published 5 or less. Journals that are highlighted in yellow are those that are known to be available for 'immediate' Open Access.

Received: 11 October 2010 Accepted: 14 October 2010 Published: 14 October 2010

doi:10.1186/1475-2875-9-284

Cite this article as: Hommel: 10 years of Malaria Journal: how did Open Access change publication patterns? Malaria Journal 2010 9:284.
Submit your next manuscript to BioMed Central and take full advantage of:

- Convenient online submission

- Thorough peer review

- No space constraints or color figure charges

- Immediate publication on acceptance

- Inclusion in PubMed, CAS, Scopus and Google Scholar

- Research which is freely available for redistribution

Submit your manuscript at www.biomedcentral.com/submit 